\title{
Review of Acoustic Emission Analysis for Snow and Avalanches
}

\author{
Shivani .G', Vandna . $B^{2}$ \\ ${ }^{1}$ PG Scholar, Department of ECE, SDDIET-Panchkula, Barwala, India \\ ${ }^{2}$ Assistant Professor, Department of ECE, SDDIET-Panchkula, Barwala, India
}

\begin{abstract}
Acoustic Emission is generation of feeble elastic waves produced by a sudden stress in a material. A structure when subjected to an external stimulus (change in pressure or temperature), localized sources trigger release of energy; waves propagate to record by sensors. The failure events which occurs inside snow results in emission of weak acoustic signatures and is responsible for failure of weak snow layers on mountain slopes leading to snow slab avalanches release. Its characterization is useful to understand the complex damage behavior of snow. This paper presents review of AE study for snow and avalanches. The distribution of various $A E$ characteristics of snow has been analyzed by numerous authors to relate them avalanche occurrence. The outcome of this study is useful to identify relevant $A E$ parameters associated with evolving damage behavior of snowpack.
\end{abstract}

Keywords: AE amplitude, counts, Cumulative AE counts, AE energy, Displace rate, Peak AE rate

\section{Introduction}

Snow is a porous structure material made up of ice, water vapor and liquid water. At homologues temperature scale the material become hot. This makes snow thermally active and structurally dynamic material. So, its properties keep on changing with time. Change in mechanical strength due to continuous evolution of snowpack, new snowfall due bad weather or any man made activity (trekker, skier etc) can create excessive stress which can lead to the failure of buried weak layer. At microscopic level failure is caused by breaking of bonds between snow grains and the released elastic energy travels as stress waves in the material and can be picked up by piezoelectric acoustic sensors. These stress waves are termed as elastic emission. An unstable buried weak layer is most frequently responsible for the failure of mountain snowpack and formation of most devastating slab avalanches. On one side, stability of a snowpack is vital information for an avalanche forecaster but on the other side it is very difficult and hazardous to get this information from real avalanche slopes. The emissions were attributed to the intra-crystal failure for low deformations and inter-crystal failure for high deformations. Most of the researchers have focused on the acoustic emission rates with snow samples subjected to different strain rates. In this paper we have reported the analysis of distribution of hits, amplitude and frequency of acoustic waves generated for different stress rates and grain sizes. The mechanical loading of rocks involves local inelastic processes that produce acoustic wave emissions (AE). Previous investigations of many materials such as snow have revealed that the microscopic failure activities are associated with the release of mechanical stresses in the form of feeble acoustic signatures, termed as acoustic emissions (AE). Acoustic emission monitoring is a non-destructive testing technique having potential research and industrial applications in the areas of flaw detection, quality control, system performance evaluation, leak detection, failure-source localization and structural health monitoring. Acoustic emissions from snow were observed in a wide frequency range depending on the size of a failure event starting from infrasonic to ultrasonic frequencies.
Coupling of AE sensors to snow is quite crucial in order to achieve the significant signal strengths of $\mathrm{AE}$ waves. The slope instability mechanism in a snowpack is associated with the microscopic failure processes going on within the snow. These processes will lead to the massive failure across a plane of the snowpack - and eventually result into an avalanche. The microscopic failure activities going on within a snowpack can be monitored through acoustic emissions generated during instability developments prior to any failure. It may help to find precursors to avalanche initiation. Soldiers are deployed at the battle sites to serve and protect our country from the wars taking place but along with this the natural hazards (avalanche, landslides, hail storm etc.) is one of the reason which has targeted them. When certain range exceeds inside the snow, uncontrollable and uncountable snow mass comes on mountain slope and occurrence of avalanche takes place which kills hundreds of soldiers every year. On one side, they are protecting us but on the other side they are killed due to natural hazards. So, we should have some solution or alarming system to save them and this Acoustic Emission technique is developed as alertness for them which are used as a real time monitoring system. So, in real time huge amount of data is collected and analyzed in microseconds. Performance of different channels is performed with the help of sensors. Different sensors reveal different information. The few AE sensors are shown in Table 1.

Table 1: AE Sensors

\begin{tabular}{|c|c|c|c|c|}
\hline Sensor type & $\begin{array}{c}\text { Operating } \\
\text { frequency } \\
\text { range(in kHz) }\end{array}$ & $\begin{array}{c}\text { Resonant } \\
\text { frequency }\end{array}$ & $\begin{array}{c}\text { Peak } \\
\text { sensitivity }\end{array}$ & $\begin{array}{c}\text { Operating } \\
\text { Temp. range } \\
\text { (in }{ }^{\circ} \text { Celsius) }\end{array}$ \\
\hline AE1(R.45I) & $1-30$ & $20 \mathrm{kHz}$ & $124 \mathrm{~dB}$ & $-35-75$ \\
\hline AE2(R1.5I) & $5-20$ & $14 \mathrm{kHz}$ & $124 \mathrm{~dB}$ & $-35-75$ \\
\hline AE3(R3I-AST) & $10-70$ & $31 \mathrm{kHz}$ & $121 \mathrm{~dB}$ & $-35-75$ \\
\hline AE4(R6I-AST) & $40-100$ & $98 \mathrm{kHz}$ & $117 \mathrm{~dB}$ & $-35-75$ \\
\hline AE5(R15I-AST) & $50-200$ & $150 \mathrm{kHz}$ & $109 \mathrm{~dB}$ & $-35-75$ \\
\hline AE6(R30I-AST) & $125-450$ & $350 \mathrm{kHz}$ & $97 \mathrm{~dB}$ & $-35-75$ \\
\hline AE7(R3 $\alpha)$ & $25-530$ & $29 \mathrm{kHz}$ & $80 \mathrm{~dB}$ & $-65-75$ \\
\hline
\end{tabular}




\section{International Journal of Science and Research (IJSR) \\ ISSN (Online): 2319-7064}

Index Copernicus Value (2013): 6.14 | Impact Factor (2014): 5.611

\section{Literature Survey}

The history of acoustic emissions starts as late as 1923, after the detection of sub-audible noise during rock-burst by Hodgson in Canada, although this report was published in 1941 (Obert, 1941) and later in 1943 (Hodgson, 1943). However, the first scientifically planned acoustic emission investigation was published in 1934 by Fuyuhiko Kishinouye. Meanwhile, Kishinouye conducted a series of experiments to detect AE from wood structures affected by seismicity (Kishinouye, 1937). For detection of very weak AE signal during deformation of Ni-steel, Förster and Sheil (1936) have used some electrical devices first time in their experiments. The fundamentals of $\mathrm{AE}$ phenomenon and material behavior during deformation and fracturing were formulated late 1950's by the efforts of Joseph Kaiser (Kaiser, 1950). The major research activities in the area of AE started after 1954 with the work of Schofield, Bareiss and Kyrala (1958) on acoustic emissions under applied stress on various materials. For the analysis of fracture initiation \& movements in different materials first time, Dunegan, Harris and Tatro (1968) have used acoustic emission as an engineering tool. St. Lawrence and Bradley (1973), who have reported it first time that spontaneous acoustic emissions (ultrasonic emissions) are generated by snow when it is close to the instability or catastrophic failure. Also, Lawrence and Bradely (1977) have reported similar observations just before the avalanche initiation. Later, Gubler (1979) has verified the previous observations of Sommerfeld, Lawrence and Bradely (1977) in the potential fracture zones of the avalanches and concluded that small amplitude AE activities are generated during instability developments and are good indicators of stability decrease in the potential fracture zones of avalanches. Considerable efforts are made by Lawrence (1980) towards formulation of $\mathrm{AE}$ based constitutive model for snow in high frequency (ultrasonic) spectrum and their applicability for avalanche release. McClung (1981) has correlated the deformation and failure pattern of alpine snow with acoustic emission rate. Sommerfeld and Gubler (1983) have analyzed the data of several years showing AE activity is greater from unstable snowpack as compared to the stable pack. They have received two types of signals from avalanches; type I spikes due to macroscopic crack generation and type II due to differential movements of the snow surfaces. The increased $\mathrm{AE}$ activity is reported with development of instabilities. Subsequently Sinha (1994) has also presented characteristics AE's from different types of polycrystalline ice. AE have been recorded with shear deformation of snow resulting due to microscopic bond failure. Further, Reiweger and others (2010) have reported that the AE counts suddenly increase before catastrophic failure of the snow. In this work we describe the performance of different designs of couplers, waveguides and arrestors, for various applications of $\mathrm{AE}$ in snow and avalanches research useful both for laboratory and field studies. Faillettaz and others (2008) showed evidence of an oscillatory behavior superimposed on the general acceleration which enables a more accurate determination of the time of rupture.

\section{(i) AE field measurements for Avalanches}

Kapil et al. (2014) have carried out extensive field work to study avalanches. For the field and the lab investigations, the acoustic arrestors and waveguides were fabricated using cylindrical rods and thin sheets of pure aluminum. For different purposes we have designed seven different types of waveguides (WG 1 to WG 7, as shown in Fig. 1(a) and AE arrestor (schematic diagram of 2D-arrestor, as shown in Fig. 1b). For the detection of AE during small fracturing events within a natural snowpack, two identical cylindrical waveguides of the type WG 5 were used which were coupled to two different types of AE sensors AE 1 (low frequency) and $\mathrm{AE} 7$ (high frequency) on the top collar of the waveguide shown in Fig. 1c).

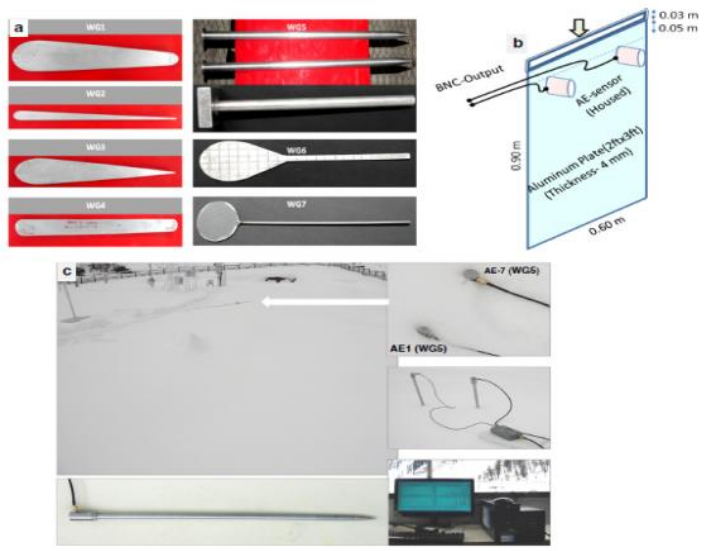

Figure 1: (a) Fabricated design of AE waveguides (WG1 toWG7), (b) Schematic design of 2-D arrestor plate for detection of AE activity from a natural snowpack, (c) Field testing of cylindrical waveguide for small artificial fracturing caused by ram penetration.

\section{(ii) Field testing to detect AE activity}

Under natural conditions, some snowpack processes may manifest themselves in the form of AE. A 2D-acoustic arrestor was deployed near the Patsio research station of SASE (as shown in Fig. 2a). AE activity recorded with meteorological conditions of air and temperature in a nearby automatic weather station (AWS). AE counts recorded during 22 hours in relation to average hours of air temperature, snow surface temperature and wind speed shown in figure 2(b). A large AE activity was observed from snowpack during natural conditions. Melting process is manifested by a 'continuous' kind of AE activity with small amplitudes (similar to one due to ductile deformation of snow), and process of freezing may have caused abrupt spikes of AE activity (burst type). The formation of ice crystals released AE.

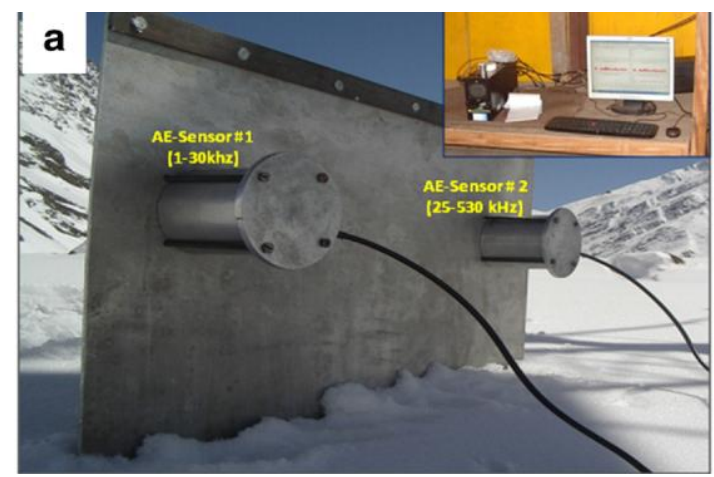

Figure 2: (a) Sensors AE $1(1 \mathrm{kHz}-30 \mathrm{kHz})$ and AE 7 (25 $\mathrm{kHz}-530 \mathrm{kHz}$ ) housed and coupled to a 2-D arrestor plate

\section{Volume 4 Issue 12, December 2015}




\section{International Journal of Science and Research (IJSR) \\ ISSN (Online): 2319-7064}

Index Copernicus Value (2013): 6.14 | Impact Factor (2014): 5.611

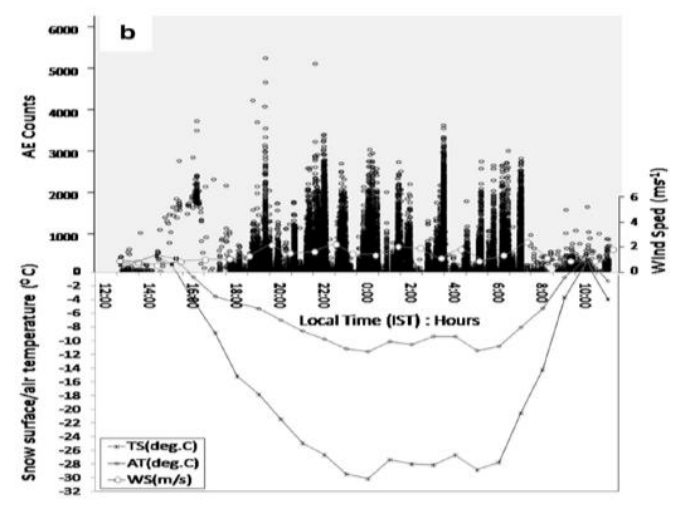

Figure 2: (b) AE counts and variation in air temperature, snow surface temperature and wind speed recorded by an automatic weather station installed near the study site

(iii) AE behavior of snow with respect to displacement AE response of snow strongly depends on the displacement rate at a particular temperature. As proposed by St. Lawrence, the sources of AE in snow may be small fractures taking place at the grain boundaries. St. Lawrence and Bradely showed that no AE activity was observed at very low displacement rates which he consequently described as a critical rate of deformation.

\section{(iv)Measurement of AE energy during fracturing of} snow

Datt et al. (2015) has measured the AE energy with fracturing of snow samples. During the multiple fractures, the AE energy was recorded with the help of a multi-channel AE system comprising the circular multi-sensor coupler and UTM testing machine. The released true AE energy during the fracturing process of the snow sample in relation to applied stress is shown in Fig. 3. There were three major spikes in the stress curve which were simultaneously replicated by three consecutive spikes in the $\mathrm{AE}$ energy suggesting a one-to-one correspondence between the mechanical stress and the released AE energy.

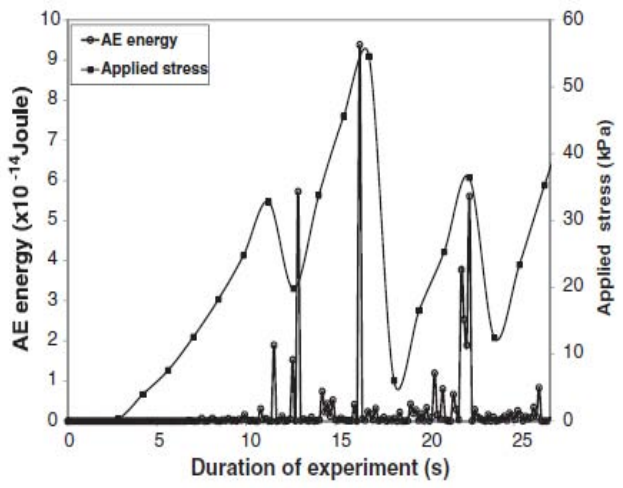

Figure 3: AE energy measured during fracturing of snow at displacement rate

\section{(v) AE amplitude}

The AE amplitude depends on the magnitude (or size) generated at the origin of any micro-fracture event occurring in a material (Datt et al., 2015). However, the AE amplitude measured experimentally also depends on many factors such as the attenuating behavior of snow, AE sensor coupling to snow, sensor characteristics and sensitivity. In the present study, the AE amplitude is defined as the peak amplitude attained by the waveform of a hit or event. A relationship between amplitude A and energy $\mathrm{E}$ can be established through measured $\mathrm{AE}$ data which should follow that $\mathrm{E}$ is directly proportional to $\mathrm{A}^{2}$, since the $\mathrm{AE}$ energy is the area under the curve of the AE waveform. Therefore, the energy of an event also depends on the event duration. The amplitude of any $\mathrm{AE}$ hit is the maximum signal voltage $\left(\mathrm{V}_{\max }\right)$, positive or negative, across the selected threshold limit and is expressed in a logarithmic scale $\left(\mathrm{dB}_{\mathrm{AE}}\right)$.

$\mathrm{A}\left(\mathrm{dB}_{\mathrm{AE}}\right)=20 \log \left(\mathrm{V}_{\max } / \mathrm{V}_{\mathrm{ref}}\right)$

\section{(vi) AE counts}

$\mathrm{AE}$ counts are the number of times the measured signal level has crossed the predefined threshold signal level (in $\mathrm{dB}_{\mathrm{AE}}$ ) in a particular $\mathrm{AE}$ hit recorded by the $\mathrm{AE}$ system. In any acoustic emission test, the AE counts represent the first level of quantified $\mathrm{AE}$ information, and are therefore of vital importance for a hit-based trend analysis generated by any random or continuous type of $\mathrm{AE}$ activity. The schematic diagram of $\mathrm{AE}$ and its parameters are shown in figure 4.

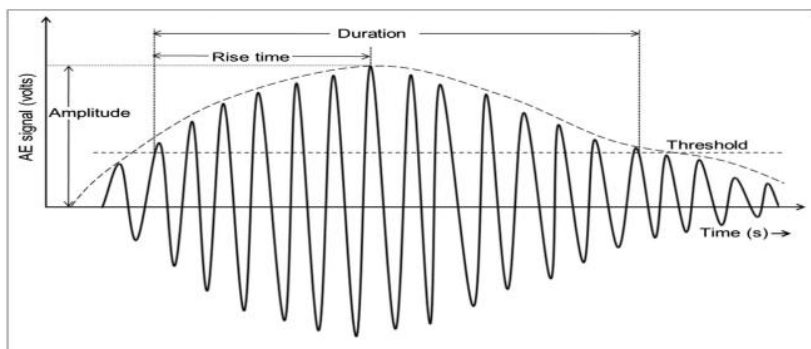

Figure 4: Schematic wave form for acoustic emission signal and various AE parameters

\section{(vii) AE Hit}

The hit duration $(t)$ is a material and source dependent parameter, defined by the difference of time between the last and the first threshold crossing. For AE activity caused by brittle failure the hit duration can usually be well defined but in the case of continuous $\mathrm{AE}$ activity the hit duration is occasionally not explicitly defined. For the data processing the sampling interval should be sufficiently smaller than that of the hit duration. For a particular spectral frequency with significant signal strength (signal level $\mathrm{N}$ threshold level), the $\mathrm{AE}$ counts $\mathrm{n}$ are directly proportional to the hit duration.

\section{(viii) AE Energy}

The AE energy is the true energy of any hit, derived from the time integral of the square of the instantaneous signal voltage $\mathrm{V}(\mathrm{t})$ over the hit duration divided by reference value of resistance. In the system used the reference resistance was $10 \mathrm{k} \Omega$. Since the AE energy level is very low, the preferred unit of the AE energy is atto Joule $(\mathrm{aJ})$ which has the value equal to $10^{-18} \mathrm{~J}$. It was developed by (SAMOS AE system and User's Manual, Rev2, 2005).

\section{(ix) AE Amplitude Distribution}

The best sensor performance among all sensors was found for sensor AE4. It is interesting to note here that the mean or median of the AE amplitude was increasing with increasing displacement rate. For slower displacement rates, the sensors AE4 and AE5 and for higher displacement rates, the sensors AE4 and AE3 have responded best in terms of the mean amplitude response.

\section{Volume 4 Issue 12, December 2015}




\section{International Journal of Science and Research (IJSR) \\ ISSN (Online): 2319-7064}

Index Copernicus Value (2013): 6.14 | Impact Factor (2014): 5.611

(x) b-Value Estimate during progressive damage of snow Datt et al. (2015) have shown a power law distribution for snow in terms of the exponent ' $b$ ' (b-value). For the low as well as the high displacement rate, the total number of events detected was relatively low in comparison to the medium displacement rate. Therefore, a window size of 500 events for $1 \mathrm{~mm} \mathrm{~min}-1$ and $10 \mathrm{~mm} \mathrm{~min}-1$ was selected for computing the temporal evolution of the b-value. In the figure 5(a), the temporal variation of b-value in relation to the load is shown. Least square (LS) and Maximum Likelihood Estimation (MSE) is revealed. In figure 5(b), the temporal evolution of the $b$-value corresponding to the displacement rate is shown.

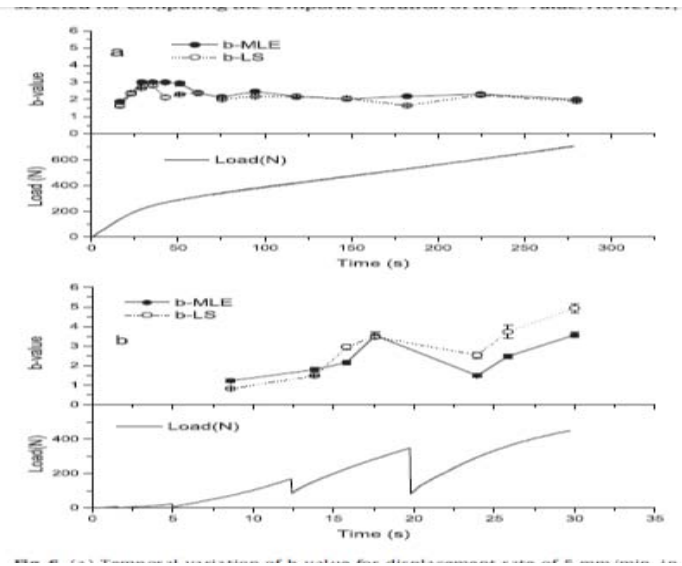

Figure 5: (a) Temporal variation of b-value for displacement rate of $5 \mathrm{~mm} / \mathrm{min}$, in relation to load response of snow, (b) b-value variation for displacement rate of 10 $\mathrm{mm} / \mathrm{min}$ vis-a-vis load response of snow

(xi) AE hit duration and damage behavior of snow A very clear dependence of $\mathrm{AE}$ hit duration on the displacement rates can be observed. Displacement rate is directly proportional to the hit duration. Fig. 6 shows the waveform duration of $\mathrm{AE}$ hits for the three displacement rates $(1 \mathrm{~mm} \mathrm{~min}-1,5 \mathrm{~mm} \mathrm{~min}-1$ and $10 \mathrm{~mm} \mathrm{~min}-1)$. Figure 6(a) shows a short duration i.e. few $\mu$ s to $800 \mu$ s. Figure 6(b) reveals that as the load is increasing with time, hit duration is also increasing. Near the yield, hit duration is maximum with duration of $830 \mu \mathrm{s}$. In the figure 6(c), there is a drastic change varying from $1000 \mu \mathrm{s}-500000 \mu \mathrm{s}$. During fracturing of snow sample, large cracks opened and large magnitude with the emission of $\mathrm{AE}$ waves but of long duration was observed. Sinha (1994) has also observed a similar type of behavior for the fracturing of shelf ice and sea ice. He attributed the longer waveforms of $\mathrm{AE}$ hits to large cracks developing within the specimen. So, AE hit duration is an important parameter of $\mathrm{AE}$ feature to represent various $\mathrm{AE}$ deformations in snow.

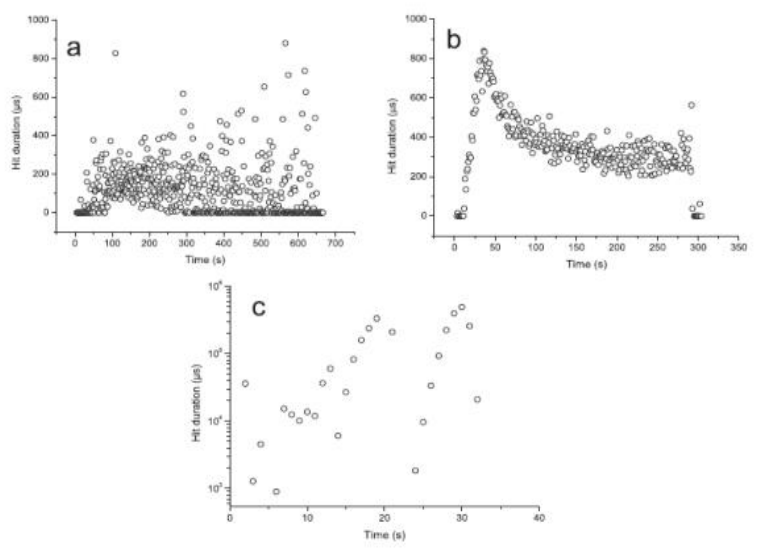

Figure 6: AE hit duration vs. displacement rate of snow for the sensor AE4 (a) hit duration for displacement rate of 1 $\mathrm{mm} / \mathrm{min}$, (b) hit duration for displacement rate of $5 \mathrm{~mm} / \mathrm{min}$,

(c) hit duration for displacement rate of $10 \mathrm{~mm} / \mathrm{min}$

(xii) The temperature-and density-dependent acoustic emission response of snow in mono-axial compression tests

In 2004, Scapozza et al. proposed the temperature dependent acoustic emission response of snow. The relationship between the applied strain rate and the measured maximum acoustic-emission rate as a function of temperature and density was found to obey a power law, which is valid for the ductile behavior range. The influence of the load history on the acoustic emissions of snow is discussed on the basis of a cyclic test, including deformation-controlled loading steps and relaxation steps, performed at different strain rates and different relaxation times. Figure 7 shows the way to calculate the power spectra of the acoustic emission signals. Acoustic emission for the snow detected using wideband sensor shown in figure 7(a). The disturbance of the signal generated by the cooling apparatus and in an interval of few minutes, it is occurred for a few seconds which is shown in figure 7(b). Snow of AE detected with the help of the sensor R6 during brittle failure as shown in figure 7(c) and the ductile range shown in 7(d) figure. The peak frequency is $500 \mathrm{kHz}$ for the wide-band sensor and $100 \mathrm{kHz}$ for the resonant sensor. The frequency distribution curves reflect the sensitivity of both sensors. These observations lead to a first conclusion, that the acoustic emission signal is a wideband signal.

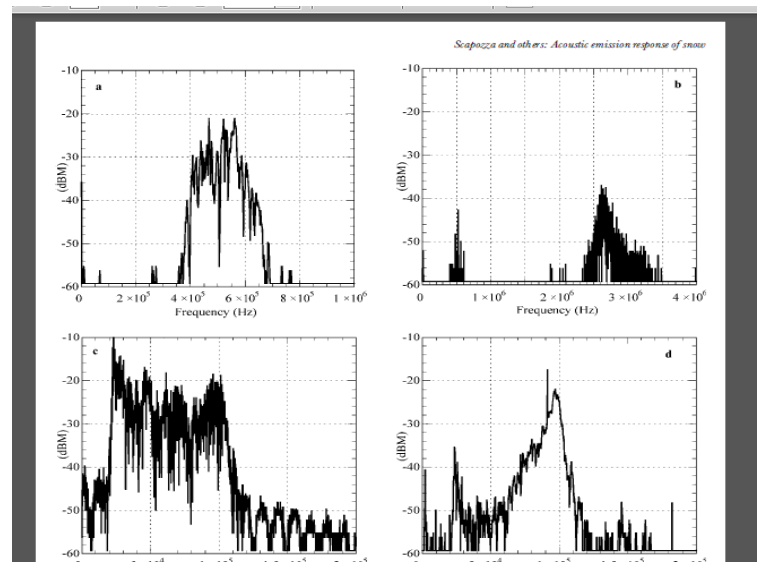

Figure 7: Power spectra for (a) acoustic emission of snow detected with the wide-band sensor WD for $\dot{\rho}=330 \mathrm{~kg} / \mathrm{m}^{3}$, $\mathrm{T}=-3.6^{\circ} \mathrm{C}$ and $\dot{\varepsilon}=1.1 \times 10^{-6}$; (b) single disturbance signals 


\section{International Journal of Science and Research (IJSR) \\ ISSN (Online): 2319-7064 \\ Index Copernicus Value (2013): 6.14 | Impact Factor (2014): 5.611}

generated by the cooling apparatus; (c) acoustic emission of snow detected with the resonant sensor R6 for a test during brittle failure for $\rho=333 \mathrm{~kg} / \mathrm{m}^{3}, \mathrm{~T}=-3.6^{\circ} \mathrm{C}$ and $\grave{\varepsilon}=2.6 \times 10^{-3}$ $\mathrm{s}^{-1}$; (d) acoustic emission of snow detected with the resonant sensor R6 for a test in the ductile range $\rho=331 \mathrm{~kg} / \mathrm{m}^{-3}, \mathrm{~T}=$ $3.8^{\circ} \mathrm{C}$ and $\grave{\varepsilon}=2.0 \times 10^{-4} \mathrm{~s}^{-1}$

(xiii) AE response of snow with Sensors (1-7)- Real time frequency dependent $\mathrm{AE}$ response of the entire resonant using circular multi-sensor arrestor base is shown in the Fig. 8 . It describes that the signal response of the sensors $(2-7)$ are relatively higher showing over 400 Hits as compared to that of the sensor 1 and 6 during its mechanical deformation. Optimum frequency range of the sensor can be identified from these observations which are lying between $10 \mathrm{KHz}$ to $200 \mathrm{KHz}$. It also should be noted that this frequency range is optimized for deformation rate near about to $5 \mathrm{~mm} /$ minute. One of the key objectives of this work was to test the applicability of the different metallic waveguides for detection of AE activity.

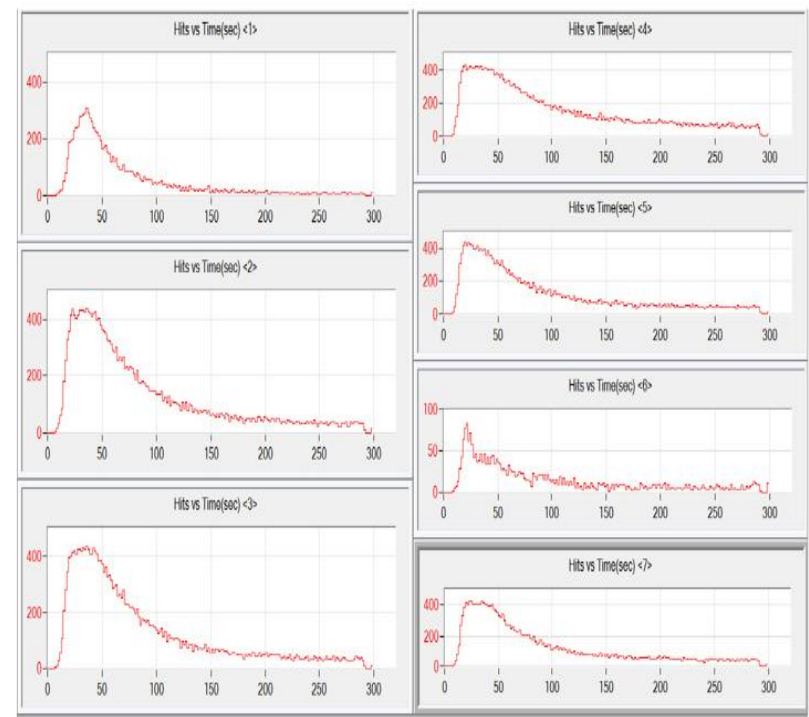

Figure 8: AE response of snow with channel 1-7 of sensors under mechanical deformation

(xiii) FFT, STFT and spectrogram Analysis

Unprocessed data of the RMS parameter (Excel file) contains a lot of noise and distortion. It does not depict clear information. So processed data with the help of Acoustic Emission Analyzer, data is filtered and channels are attached to the sensors which cannot be done in unprocessed data. There is no provision of these AE parameters and analytical functions like Average, Maximum, Minimum and Total second wise value. Further, FFT and STFT and its spectrogram have been done. FFT is easier and is in frequency domain. It is not precise and does not give any information about time domain. The sensor AE7 is shown in figure 9(a) and (b). FFT is shown in below. It reveals the magnitude response and the phase response with respect to the normalized frequency. This diagram describes that Channel 7 has minimum distortion. Its magnitude is of 79 $\mathrm{dB}$ of minimum frequency and maximum frequency. Its peak frequency is $130 \mathrm{kHz}$ and $365 \mathrm{kHz}$. The other frequency components are first decreasing, then constant and then increasing. The change is abrupt and step-wise. The phase response is very good, it is first decreasing till $60 \mathrm{kHz}$ and then increasing $130 \mathrm{kHz}$ and then a decrease till 380 $\mathrm{kHz}$ and then abrupt increase. STFT is shown in figure 9(b). It represents the frequency $(\mathrm{kHz}) \mathrm{Vs}$ time graph.

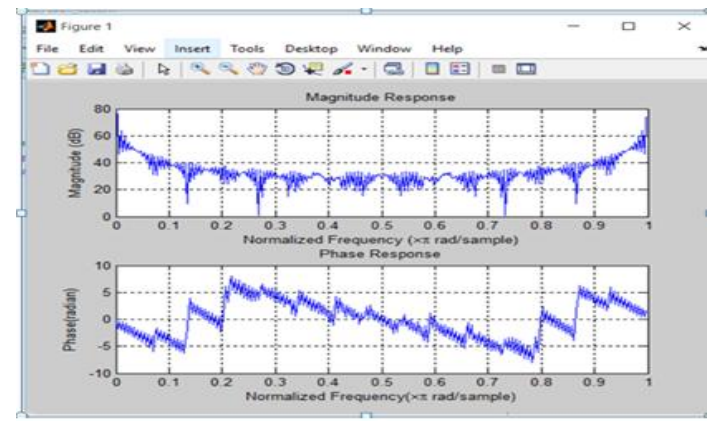

Figure 9: (a) FFT analysis of AE signal

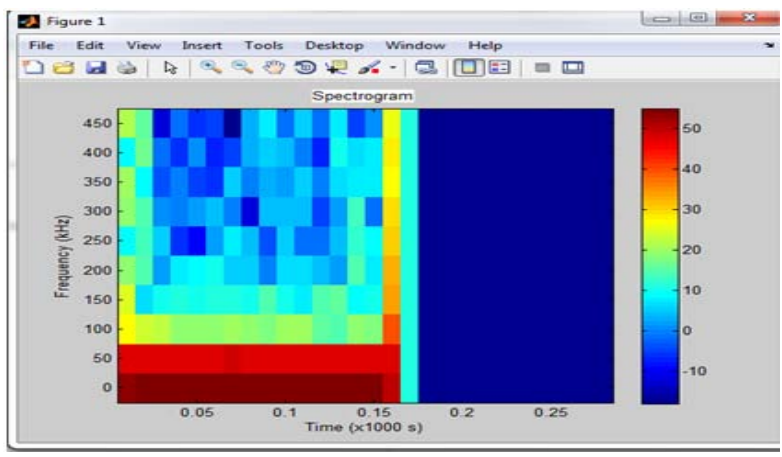

Figure 9: (b) STFT and Spectrogram Analysis

\section{Conclusion}

St. Lawrence did the first research on the study of snow and avalanche. These stress waves are termed as elastic emissions who were the pioneers for detecting acoustic emissions in the lab from deforming snow. Scapozza in 2004 studied on the temperature and density dependent Acoustic Emission response of snow in mono-axial compression tests. He also carried out compression tests on snow specimen in laboratory conditions for different strain rates. Gubler in 1979 proposed Acoustic emission as an indicator of stability decrease in fracture zones of avalanches. The work is still in process on these related research as there is instability of slope on snow. So, for real time monitoring acoustic emission analysis tool was developed for the high speed acoustic data and its analysis was done. It finds its wide applications for forecasting avalanches.

\section{References}

[1] Bowles, D., St. Lawrence,W.F., 1977. Acoustic emissions in the investigation of avalanches. Proceedings of the 45th Annual Western Snow Conference, April 18-21, 1977, Albuquerque, New Mexico.

[2] Gubler, H., 1979. Acoustic Emission as an indicator of stability decrease in fracture zones of avalanches. J. Glaciol.

[3] Johnson, J.B., 1982. On the application of Biot's theory to acoustic wave propagation in snow. Cold Reg. Sci. Technol.

[4] Kapil, J.C., Prasher, C., Chasmai, M., Satyawali, P.K., 2009. A Parallel-Probe Saturation Profiler: a new

\section{Volume 4 Issue 12, December 2015}




\section{International Journal of Science and Research (IJSR) \\ ISSN (Online): 2319-7064}

Index Copernicus Value (2013): 6.14 | Impact Factor (2014): 5.611

technique for fast profiling of meltwater saturation in a seasonal snowpack. J. Glaciol.

[5] Kinosita, S., 1967. Compression of snow at constant speed. In: Oura, H. (Ed.), Physics of Snow and Ice, vol. I. Inst. of Low Temp.

[6] Scapozza, C., Bucher, F., Amann, P., Ammann, W.J., Bartelt, P., 2004. The temperature and density dependent Acoustic Emission response of snow in mono-axial compression tests. Ann. Glaciol.

[7] Sinha, N.K., 1994. Characteristics of Acoustic Emission from different types of polycrystalline Ice. Proc. Snow Symposium 94. Ontario, Canada.

[8] St. Lawrence, W.F., 1980. The Acoustic Emission response of snow. J. Glaciol.

[9] St. Lawrence, W.F., Bradely, C.C., 1977. Spontaneous fracture initiation inmountain snowpack. J. Glaciol.

[10] St. Lawrence, W.F., Williams, T.R., 1976. Seismic signals associated with avalanches. J. Glaciol.

[11] McClung, D.M., 1981. Failure characteristics of Alpine snow in slope deformation. Proc., International Symposium on the mechanical behavior of structured media. Ottawa, Canada.

[12] Amitrano, Variability in the power-law distributions of rupture events, How and why does b-value change. European Physical Journal - Special Topics, EDP Sciences: EPJ, 2012.

[13] J'erome FAILLETTAZ. Icequakes coupled with surface displacements for predicting glacier break-off in 2011 .

[14] Aaron Clauset. Power-law distributions in empirical data in 2009. 